\title{
Temperature-Dependent Phonon Shifts in Mono-layer, Few-layer, and Bulk WS 2 Films
}

\author{
LIU Xinke, WANG Jiale, XU Chuyu, LUO Jiangliu, LIANG Disi, CEN Yunuo, LÜ Youming, LI Zhiwen * \\ College of Materials Science and Engineering, Shenzhen Key Laboratory of Special Functional Materials, Nanshan District Key Lab \\ for Biopolymer and Safety Evaluation, Shenzhen University, Shenzhen 518060, Guangdong Province, P. R. China.
}

\begin{abstract}
Two-dimensional transition metal disulfides (TMDs) have recently attracted significant research attention due to their rich physical and chemical properties. Graphene has also been studied intensively due to its high electron mobility of $\sim 200000 \mathrm{~cm}^{2} \cdot \mathrm{V}^{-1} \cdot \mathrm{s}^{-1}$. Since there is no band gap, it is difficult for a graphene-based device to achieve high current on/off ratio. For TMDs, such as $\mathrm{MoS}_{2}, \mathrm{MoSe}_{2}, \mathrm{WS} \mathrm{S}_{2}$, and $\mathrm{WS}_{2}$, the band gaps of these materials can be adjusted according to the number of layers. Since TMD has the advantage of suppressing source-drain tunneling current in an

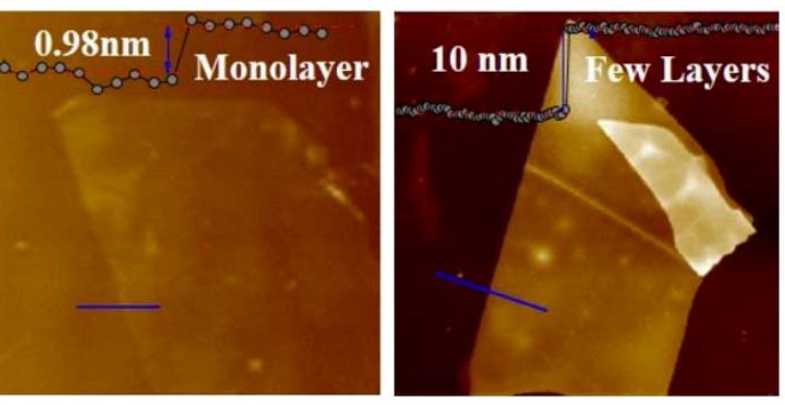
ultra-short transistor and offering superior immunity to short-channel effects, it is also attractive for use as a channel material in Si complementary metal oxide semiconductor (CMOS) devices larger than $22 \mathrm{~nm}$. Among them, $\mathrm{MoS}_{2}$ in singlelayer and multi-layer films have been intensively researched for many years. MoS $\mathrm{S}_{2}$-based field effect transistors (FETs) with excellent electrical properties have been reported. WS 2 has lower in-plane electronic mass than $\mathrm{MoS}_{2}, \mathrm{MoSe}_{2}$, and $\mathrm{MoTe}_{2}$, and therefore has potential for higher carrier mobility or higher output current for WS $\mathrm{W}_{2}$-based FETs. Experimental research on $\mathrm{WS}_{2}$ is limited compared to $\mathrm{MoS}_{2}$, and more work is needed to further exploit the full potential of WS $\mathrm{S}_{2}$-based FETs. Therefore, the electron-phonon interaction and vibration properties of $\mathrm{WS}_{2}$ used in nano-electronic applications and FETs must be investigated. To this end, mono-layer (1L), few-layer (FL), and bulk $\mathrm{WS}_{2}$ films were prepared using mechanical exfoliation from a WS 2 crystal. $3 \mathrm{M}$ scotch-tape was used for transferring the $\mathrm{WS}_{2}$ films. Detailed temperaturedependent Raman study on $1 \mathrm{~L}, \mathrm{FL}$, and bulk WS 2 films has been conducted using a 514-nm excitation laser. Raman spectroscopy, as an effective and non-destructive approach for phonon vibration study, has been used to evaluate TMDs. The Raman spectra reveal much useful information on the test sample in terms of peak position and spectral shape change. With the film thickness increasing to bulk, the $A_{1 \mathrm{~g}}(\Gamma)$ and $E_{2 \mathrm{~g}}^{1}(\Gamma)$ modes show blue-shift and red-shift, respectively, with respect to $1 \mathrm{~L} \mathrm{WS}_{2}$. Moreover, when the dominant Raman vibration modes swaps between $E_{2 \mathrm{~g}}^{1}(\Gamma)$ and $A_{1 \mathrm{~g}}(\Gamma)$, the "crossover" temperature was identified for $1 \mathrm{~L}, \mathrm{FL}$, and bulk WS $\mathrm{W}_{2}$ films. WS $\mathrm{W}_{2}$ shows smaller frequency change $\Delta$ between the $E_{2 g}^{1}(\Gamma)$ and $A_{1 \mathrm{~g}}(\Gamma)$ modes than $\mathrm{MoS}_{2}$, with varying film thickness. The temperature coefficient of the Raman peak position was one magnitude lower for $\mathrm{WS}_{2}$ than $\mathrm{MoS}_{2}$, implying that $\mathrm{WS}_{2}$ has better thermal stability than $\mathrm{MoS}_{2}$. The results of this systematic study provide a physical guidance for $\mathrm{WS}_{2}$-based device design.
\end{abstract}

Key Words: WS$_{2}$; Film thickness; Raman; Photoluminescence; Vibration mode

Received: September 10, 2018; Revised: October 12, 2018; Accepted: November 1, 2018; Published online: November 5, 2018.

*Corresponding author. Email: lizhiwen2017@email.szu.edu.cn; Tel.: +86-15889506637.

The project was supported by the National Key Research and Development Plan (2017YFB0403000), the National Natural Science Foundation of China (61504083), the Public Welfare Capacity Building in Guangdong Province, China (2015A010103016), the Science and Technology Foundation of Shenzhen, China (JCYJ20160226192033020), the Natural Science Foundation of Guangdong Province, China (2016A030313060), the PhD Start-up Fund of Natural Science Foundation of Guangdong Province, China (2017A030310424), the Natural Science Foundation of SZU, China (000062), and the National Taipei University of Technology-Shenzhen University Joint Research Program, China (2018001).

国家重点研究发展计划(2017YFB0403000), 国家自然科学基金(61504083), 广东省公益能力建设(2015A010103016), 深圳科学和技术基础 (JCYJ20160226192033020), 广东省自然科学基金(2016 A030313060), 广东省自然科学基金博士启动基金(2017A030310424), 深圳大学自然科学基 金(000062), 国立台北科技大学深圳大学联合研究(2018001)资助项目

(C) Editorial office of Acta Physico-Chimica Sinica 


\title{
单层，少层和块状 $\mathbf{W S}_{2}$ 薄膜中声子位移随温度的变化
}

\author{
刘新科, 王佳乐, 许楚瑜, 罗江流, 梁迪斯, 岑俞诺, 吕有明, 李治文* \\ 深圳大学材料科学与工程学院, 深圳市特种功能材料重点实验室, 深圳大学南山区生物聚合物与安全评价重点实验室, \\ 广东深圳 518060
}

\begin{abstract}
摘要：近年来，二维过渡金属二硫化物(TMD)由于其良好的物理和化学性质而引起人们的关注。其中，石墨烯由于其高 达 $200000 \mathrm{~cm}^{2} \cdot \mathrm{V}^{-1} \cdot \mathrm{s}^{-1}$ 高电子迁移率得到了深入研究。由于石墨烯没有带隙, 因此基于石墨烯的器件难以实现高的电流 开关比。对于二维过渡金属二硫化物例如 $M_{0} S_{2} 、 \mathrm{MoSe}_{2} 、 W \mathrm{We}_{2}$ 和WS $\mathrm{S}_{2}$, 这些材料可以根据层数来调节的带隙。其中, 单层和多层MoS 2 薄膜已进行了广泛深入研究。已经有人实现具有优异电学性能的基于 $M_{0} S_{2}$ 的场效应晶体管(FET)。与 $\mathrm{MoS}_{2} 、 \mathrm{MoSe}_{2}$ 和 $\mathrm{MoTe}_{2}$ 相比, WS $\mathrm{S}_{2}$ 具有更低的面内电子质量, 这表明基于 $\mathrm{WS}_{2}$ 的FET具有更高的载流子迁移率或更高的 输出电流。与 $\mathrm{MOS}_{2}$ 相比, $\mathrm{WS}_{2}$ 缺乏系统的研究, 需要更多的研究工作来进一步发掘基于 $\mathrm{WS}_{2}$ 的场效应晶体管的潜能。因 此, 我们使用机械剥离法来制备 $\mathrm{WS}_{2}$ 晶体单层 $(1 \mathrm{~L})$, 少层 $(\mathrm{FL})$ 和块状 $\mathrm{WS}_{2}$ 薄膜。使用 $3 \mathrm{M}$ 透明胶带转移 $\mathrm{WS}_{2}$ 薄膜, 并且使 用 $514 \mathrm{~nm}$ 激光器对 $1 \mathrm{~L} 、 F L$ 和块状WS $S_{2}$ 膜进行了变温的拉曼研究。随着膜厚度增加到块状, 对于 $1 \mathrm{LWS}, A_{19}(\Gamma)$ 和 $E_{2 g}{ }_{2}(\Gamma)$ 模式分别显示蓝移和红移。此外, 当拉曼振动模式在 $E^{1}{ }_{2 g}(\Gamma)$ 和 $A_{1 g}(\Gamma)$ 之间交换时, “交叉” 温度被识别为 $1 \mathrm{~L} 、 F L$ 和块状WS 2 膜。与 $\mathrm{MoS}_{2}$ 相比, 随着膜厚度的变化, $\mathrm{WS}_{2}$ 在 $E_{2 g}^{1}(\Gamma)$ 和 $A_{1 \mathrm{~g}}(\Gamma)$ 之间表现出较小的频率变化 $(\Delta)$, 并且从拉曼峰值位置随温 度变化来看, $W_{2}$ 比 $M_{0} S_{2}$ 少一个量级。这项工作为基于 $W_{2}$ 的器件设计提供了物理指导。
\end{abstract}

关键词: 二硫化铇; 薄膜厚度; 拉曼; 光致发光; 振动模式 中图分类号: 0641

\section{Introduction}

Two-dimensional transition metal dichalcogenides (TMDs) have recently gained much interest due to their rich physical and chemical properties, which enable the future applications in nano-electronics ${ }^{1,2}$, nano-photonics ${ }^{3-5}$, and valley-electronics ${ }^{6-8}$. The counterpart graphene, has also been intensively investigated due to its high electron mobility $200000 \mathrm{~cm}^{2} \cdot \mathrm{V}^{-1} \cdot \mathrm{s}^{-1}$, since its first mechanical exfoliation by Novoselov et al. in $2004{ }^{9,10}$. However, due to its absence of bandgap, to achieve high current on/off ratio is difficult for graphene-based devices. Several techniques have been proposed to create the bandgap for graphene. For example, employing quantum mechanical confinement in patterned ${ }^{11}$ or exfoliated graphene nano-ribbons ${ }^{12}$ introduces a bandgap up to $400 \mathrm{meV}$, and applying perpendicular electric field (voltage exceeding $100 \mathrm{~V}$ ) in bi-layer graphene creates a bandgap up to $250 \mathrm{meV}{ }^{13}$. These innovative methods of introducing a bandgap in graphene always come with a price of significant mobility degradation $\left(\sim 200 \mathrm{~cm}^{2} \cdot \mathrm{V}^{-1} \cdot \mathrm{s}^{-1}\right)$, process complexity, or device reliability under high voltage ${ }^{14-16}$. For TMDs, such as $\mathrm{MoS}_{2}, \mathrm{MoSe}_{2}, \mathrm{WSe}_{2}$, and $\mathrm{WS}_{2}$ etc, these materials have a bandgap, which is tunable based on the number of layer. Usually, the bandgap of the bulk TMDs is $\sim 1.2-1.3 \mathrm{eV}$, and one of mono-layer TMDs is $\sim 1.8-2.1 \mathrm{eV}$, the increase of bandgap with decreasing number of layer for TMDs is due to the carrier quantum confinement at an atomic scale. Being able to achieve atomic thickness and have a bandgap larger than that of silicon, TMDs are also attractive for being used as the channel material for Si CMOS devices beyond sub- $22 \mathrm{~nm}$, since TMDs have advantage for suppressing the source-to-drain tunneling current in ultra-short transistors and offering superior immunity to short-channel effects ${ }^{17}$.

Among TMD group, $\mathrm{MoS}_{2}$ in both mono- and few-layer films has been intensively studied in the research community over the years ${ }^{18-23}$. $\mathrm{MoS}_{2}$-based field effect transistors (FETs) with excellent electrical characteristics have been demonstrated, such as high current on/off ratio $\left(\sim 10^{8}\right)$, low subthreshold swing $(\sim 70$ $80 \mathrm{mV} \cdot \mathrm{dec}^{-1}$ ), mobility up to $\sim 200 \mathrm{~cm}^{2} \cdot \mathrm{V}^{-1} \cdot \mathrm{s}^{-1}$ (in high$k / \mathrm{MoS}_{2} /$ high- $k$ structure) ${ }^{24}$. As a typical TMD, $\mathrm{WS}_{2}$ has been widely used due to its potential excellent performance ${ }^{25}$. Similar to $\mathrm{MoS}_{2}, \mathrm{WS}_{2}$ can also be grown through chemical vapor deposition (CVD) ${ }^{26}$. According to the simulation work by Liu et al. ${ }^{27}, \mathrm{WS}_{2}$ have a lower in-plane electronic mass, compared with $\mathrm{MoS}_{2}, \mathrm{MoSe}_{2}$, and $\mathrm{MoTe}_{2}$, which shows the potential for higher carrier mobility or higher output current for $\mathrm{WS}_{2}$-based FETs. However, as compared with $\mathrm{MoS}_{2}$, the experimental studies on $\mathrm{WS}_{2}$ are limited, or more work is required to be done for further harnessing the full potential of $\mathrm{WS}_{2}$-based FETs. In the literature, mono- and multi-layer $\mathrm{WS}_{2}$-based FETs were demonstrated, and achieved on/off current ratio of $\sim 10^{6}-10^{8}$ with mobility of $\sim 140-234 \mathrm{~cm}^{2} \cdot \mathrm{V}^{-1} \cdot \mathrm{s}^{-1} 28-30$.

As for the nano-electronic application, it is important to investigate the electron-phonon interaction and vibration properties of $\mathrm{WS}_{2}$. Raman spectroscopy, as an effective and nondestructive approach for phonon vibration study, has been used to evaluate graphene, and TMDs ${ }^{31-33}$. Raman spectra reveal much useful information of the test sample through Raman peak position and Raman shape change. Temperature dependent phonon shifts of single layer $\mathrm{WS}_{2}$ by mechanical exfoliation ${ }^{34}$ 
and multi-layer $\mathrm{WS}_{2}$ by hydrothermal method ${ }^{35}$, have been investigated by Raman spectroscopy. In this work, we present thickness- and temperature-dependent studies of the phonon vibration mode for mono-layer, few-layer, and bulk $\mathrm{WS}_{2}$ films prepared by mechanical exfoliation.

\section{Experimental}

The mono-layer (1L), few-layer (FL), and bulk $\mathrm{WS}_{2}$ films were prepared on $300 \mathrm{~nm} \mathrm{SiO}_{2} / \mathrm{Si}$ wafer by mechanical exfoliation from bulk $\mathrm{WS}_{2}$ crystal, which was purchased from 2D Semiconductor Inc. 3M scotch-tape was used for transferring the $\mathrm{WS}_{2}$ films. Raman and photoluminescence (PL) spectra were collected in a Renishaw inVia confocal system in the backscattering configuration. The wavelength of the laser was $514 \mathrm{~nm}(2.4 \mathrm{eV})$ from an argon ion laser, the grating of 2400 grooves $\mathrm{mm}^{-1}$ was used to obtain more details of line shapes of the Raman band. The laser power on the sample was set at around $1.0 \mu \mathrm{W}$ to avoid laser induced heating. The application of a $100 \times$ objective lens with a numerical aperture of 0.9 can provide us a spot size of $\sim 1 \mu \mathrm{m}$, and spectral resolution was 1 $\mathrm{cm}^{-1}$. The Si peak at $520 \mathrm{~cm}^{-1}$ was used as a reference for wavelength calibration. Atomic force microscopy (AFM) images were obtained under tapping mode using Bruker Dimension Icon.

\section{Rseults and Discussion}

The atomic force microscopy (AFM) images of 1L, FL, and bulk $\mathrm{WS}_{2}$ films are shown in Fig. 1a, b, and c. The film thickness was directly measured by AFM in a non-contact mode. As shown in Fig. 1d, e, and f, the step height or thickness of 1L, FL, and bulk $\mathrm{WS}_{2}$ films were measured to be $0.98,10$, and $76 \mathrm{~nm}$. Based on the reported mono-layer $\mathrm{WS}_{2}$ thickness of $\sim 0.9 \mathrm{~nm}$, the number of layer for $0.98,10$, and $76 \mathrm{~nm}$ is determined to be $1 \mathrm{~L}$, $\sim 11 \mathrm{~L}$, and $\sim 84 \mathrm{~L}$, respectively. In Fig. 2, PL spectra were measured using a $514 \mathrm{~nm}$ excitation laser. It is known that the bulk $\mathrm{WS}_{2}$ is an indirect bandgap semiconductor with $\mathrm{a} \sim 1.3 \mathrm{eV}$ bandgap, whereas $1 \mathrm{~L} \mathrm{WS}_{2}$ has a direct bandgap of $\sim 2.1 \mathrm{eV}$. For the bulk $\mathrm{WS}_{2}$, the electron states involved in the indirect transition (the valence band maximum at $\Gamma$ point and the conduction band minimum at $T$ point) originate from linear combination of tungsten $d$-orbital and sulfur $p_{z}$-orbital, and their dispersion strongly depends on the number of layers. For the $1 \mathrm{~L}$ $\mathrm{WS}_{2}$, the electron states involved in the direct transition (the valence band maximum at $K$ point and the conduction band minimum at $K$ point) mainly originate tungsten $d$-orbital, and their energies are not very sensitive to the number of layers ${ }^{36}$. In Fig. 2, one sharp PL peak centered at $\sim 638.5 \mathrm{~nm}$ is observed for $1 \mathrm{~L} \mathrm{WS}_{2}$ and the measured spectral range nearly vanishes for the FL $\mathrm{WS}_{2}$ sample. When the thickness decreases to $1 \mathrm{~L}$, the dramatic increase of the PL intensity is a signature of the transformation from indirect to direct bandgap structures. Based on the PL peak for 1L WS 2 shown in Fig. 2, the bandgap of 1L $\mathrm{WS}_{2}$ is estimated from the PL peak to be $\sim 1.94 \mathrm{eV}$, which is smaller than $\sim 2.1 \mathrm{eV}$. Direct electronic transitions in $1 \mathrm{~L} \mathrm{WS}_{2}$ originate from exitonic radiative relaxation, and for this reason the PL peak signal always appears at energies slightly lower than $\sim 2.1 \mathrm{eV}$ direct bandgap of $\mathrm{WS}_{2}$.

Raman studies of $1 \mathrm{~L}, \mathrm{FL}$, and bulk $\mathrm{WS}_{2}$ films have been carried out using a $514 \mathrm{~nm}$ excitation laser, since Raman spectrum of $\mathrm{WS}_{2}$ under a $514 \mathrm{~nm}$ excitation laser becomes very
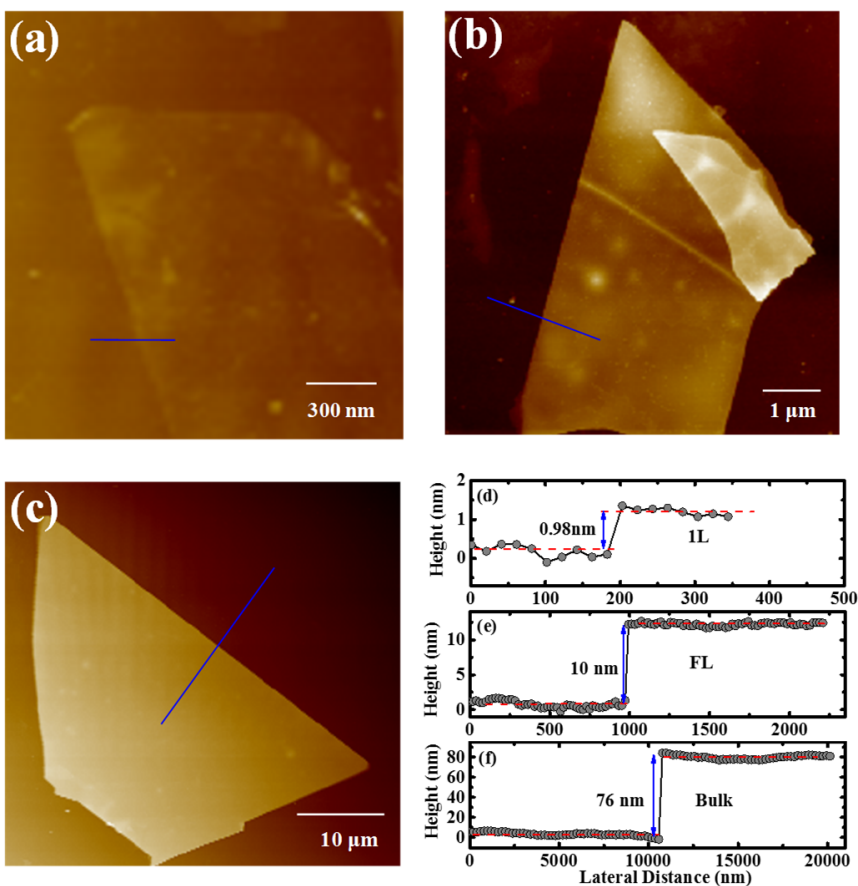

Fig. 1 The atomic force microscopy (AFM) images of (a) 1L, (b) FL, and (c) bulk WS $\mathrm{S}_{2}$ films.

The step height or thickness of (d) $1 \mathrm{~L}$, (e) FL, and (f) bulk $\mathrm{WS}_{2}$ films. 


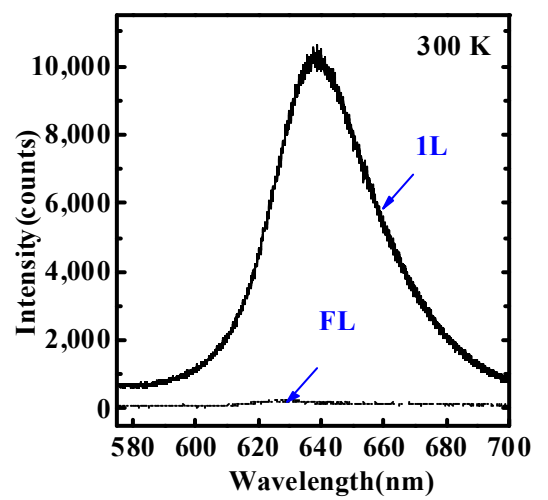

Fig. 2 Photoluminescence spectra from FL to 1L. One sharp PL peak centered at $\sim 638.5 \mathrm{~nm}$ for $1 \mathrm{~L} \mathrm{WS}$, however nearly no peak for the FL sample.

rich, revealing many second-order peaks ${ }^{37,38}$. Raman spectra at $300 \mathrm{~K}$ of $1 \mathrm{~L}, \mathrm{FL}$, and bulk $\mathrm{WS}_{2}$ films are shown in Fig. 3a, b, and c. Raman active modes of $\mathrm{WS}_{2}$ comprise of $A_{1 \mathrm{~g}}, E_{1 \mathrm{~g}}, E_{2 \mathrm{~g}}^{1}$, and $E_{2 \mathrm{~g}}^{2}$ at the center of the Brillouin zone, but $E_{1 \mathrm{~g}}$ is forbidden in the back-scattering configuration and $E_{2 \mathrm{~g}}^{2}$ is less studied due to its low frequency out of the most conventional Raman spectral range. The $A_{1 \mathrm{~g}}$ mode is related to the out-of-plane vibration of sulfur atoms, and the $E_{2 \mathrm{~g}}^{1}$ mode is associated with the in-plane vibration of tungsten and sulfur atoms. Under a $514 \mathrm{~nm}$ excitation laser, the $A \lg (\Gamma)$ mode was observed at $419 \mathrm{~cm}^{-1}$ and dominant $2 L A(M)$ mode observed at $\sim 350 \mathrm{~cm}^{-1}$ overlapping with $E_{2 \mathrm{~g}}^{1}(\Gamma)$ mode $\left(\sim 355 \mathrm{~cm}^{-1}\right)$, which was acquired by multiLorentzian fitting. Fig. $3 \mathrm{~d}$, e, and $\mathrm{f}$ show the multi-Lorentzian fitting of $2 L A(M)-2 E_{2 \mathrm{~g}}^{2}(\Gamma), E_{2 \mathrm{~g}}^{1}(M), 2 L A(M)$, and $E_{2 \mathrm{~g}}^{1}(I)$ modes for $1 \mathrm{~L}, \mathrm{FL}$, and bulk $\mathrm{WS}_{2}$ films, respectively. When the number of layer increases from $1 \mathrm{~L}$ to bulk, the $A \lg (\Gamma)$ mode shows a blueshift of $1.34 \mathrm{~cm}^{-1}$ from 419.14 to $420.48 \mathrm{~cm}^{-1}$, similar to the trend observed for $\mathrm{MoS}_{2}$, as the van der Waals interactions between the layers increase the restoring force in the thicker layers. On the other hand, $E_{2 \mathrm{~g}}^{1}(\Gamma)$ mode shows a red-shift of 0.69 $\mathrm{cm}^{-1}$ from 354.59 (1L) to $353.90 \mathrm{~cm}^{-1}$ (bulk), which is attributed to the increment of dielectric long-range coulomb interactions among the effective charges. It is worth noting that in $\mathrm{WS}_{2}$, the close proximity of the $2 L A(M)$, and $E_{2 \mathrm{~g}}^{1}(\Gamma)$ modes increases the error in determining the frequency shift. As compared with $\mathrm{MoS}_{2}$, the $A_{1 \mathrm{~g}}(\Gamma)$ blue-shift of $1.34 \mathrm{~cm}^{-1}$ and the $E_{2 \mathrm{~g}}^{1}(\Gamma)$ red-shift of $0.69 \mathrm{~cm}^{-1}$ of WS 2 are much smaller, as the $A_{1 \mathrm{~g}}$ blue-shift and the $E_{2 \mathrm{~g}}^{1}$ red-shift of $\mathrm{MoS}_{2}$ as increasing $1 \mathrm{~L}$ to bulk is $\sim 4.2$ and 2.2 $\mathrm{cm}^{-1}$, respectively. As shown in Fig. 3, the frequency difference ( $\triangle$ ) between $A_{1 \mathrm{~g}}(\Gamma)$ and $E_{2 \mathrm{~g}}^{1}(\Gamma)$ modes is varied from 64.55 to $66.58 \mathrm{~cm}^{-1}$, when the number of WS 2 layer increases from $1 \mathrm{~L}$ to bulk. The $\Delta$ between $A_{1 \mathrm{~g}}(\Gamma)$ and $E_{2 \mathrm{~g}}^{1}(\Gamma)$ modes for $1 \mathrm{~L} \mathrm{WS}_{2}$ prepared by mechanical exfoliation is reported to be $64 \mathrm{~cm}^{-1}$ by Thripuranthaka et al. ${ }^{34}$. In the literature, $\Delta$ between $A_{1 \mathrm{~g}}(\Gamma)$ and $E_{2 \mathrm{~g}}^{1}(I)$ modes is also increased from $\sim 62$ to $65 \mathrm{~cm}^{-1}$, when the number of $\mathrm{WS}_{2}$ layer increases from $1 \mathrm{~L}$ to bulk prepared by chemical vapor deposition (CVD) method. Although this observed trend is similar to that of $\mathrm{MoS}_{2}$, there are a larger $\Delta$ change between $A_{1 \mathrm{~g}}(\Gamma)$ and $E_{2 \mathrm{~g}}^{1}(\Gamma)$ modes (from $\sim 19$ to $\sim 25$ $\mathrm{cm}^{-1}$ ), when the number of $\mathrm{MoS}_{2}$ layer increases from $1 \mathrm{~L}$ to bulk. It is noted that the $\Delta\left(\sim 18 \mathrm{~cm}^{-1}\right)$ between $A_{1 \mathrm{~g}}$ and $E_{2 \mathrm{~g}}^{1}$ modes for the $1 \mathrm{~L} \mathrm{MoS}_{2}$ by mechanical exfoliation is smaller than that of $1 \mathrm{~L} \mathrm{MoS} 2$ by CVD method $\left(\sim 19 \mathrm{~cm}^{-1}\right)$. However, based on the reported values in the literature, the case for $\mathrm{WS}_{2}$ is opposite, since the $\Delta\left(\sim 64 \mathrm{~cm}^{-1}\right)$ between $A_{1 \mathrm{~g}}(\Gamma)$ and $E_{2 \mathrm{~g}}^{1}(\Gamma)$ modes for the $1 \mathrm{~L} \mathrm{WS}_{2}$ by mechanical exfoliation is larger than that $\left(\sim 62 \mathrm{~cm}^{-1}\right)$ of $1 \mathrm{~L} \mathrm{WS} \mathrm{W}_{2}$ by CVD method. Further, it looks that Raman vibration mode for $\mathrm{WS}_{2}$ is less sensitive to the number of layer as compared to $\mathrm{MoS}_{2} . \Delta$ between $A_{1 \mathrm{~g}}$ and $E_{2 \mathrm{~g}}^{1}$ modes is often used to identify the number of layer in $\mathrm{MoS}_{2}$ films. Due to the less sensitivity of $\Delta$ between $A_{1 \mathrm{~g}}(\Gamma)$ and $E_{2 \mathrm{~g}}^{1}(\Gamma)$ modes to the number of layer for $\mathrm{WS}_{2}$, more accurate or robust method is needed for identifying the number of layer in $\mathrm{WS}_{2}$ films, except for the AFM direct measurement method.

Temperature-dependent Raman measurements of $1 \mathrm{~L}, \mathrm{FL}$, and bulk $\mathrm{WS}_{2}$ films have been carried out at 80-300 K under a 514 $\mathrm{nm}$ excitation laser, and the results are show in Fig. 4a, b, and c. In this part, we will focus on the discussion about peak intensity ratio $\left[2 L A(M) / A_{1 \mathrm{~g}}(\Gamma), E_{2 \mathrm{~g}}^{1}(\Gamma) / A_{1 \mathrm{~g}}(\Gamma)\right.$, etc.] and peak position as a function of temperature. In viewing of $\mathrm{WS}_{2}$ as the potential CMOS channel material beyond $\mathrm{Si}$, it is important to study the electron-phone interactions or vibration modes under various temperatures through non-destructive Raman method. The temperature-dependent Raman vibration modes of $\mathrm{WS}_{2}$ can have a direct bearing on the carrier transport of $\mathrm{WS}_{2}$-based FETs. As shown in Fig. 5, the $2 L A(M) / A_{1 \mathrm{~g}}(\Gamma), E_{2 \mathrm{~g}}^{1}(\Gamma) / A_{1 \mathrm{~g}}(\Gamma)$, and Rec. $\left[2 L A(M), E^{1}{ }_{2 \mathrm{~g}}(\Gamma)\right] / A_{1 \mathrm{~g}}(\Gamma)$ peak intensity ratio are plotted as a function of temperature for (a) $1 \mathrm{~L}$, (b) FL, and (c) bulk $\mathrm{WS}_{2}$. Rec. $\left[2 L A(M), E^{1}{ }_{2 \mathrm{~g}}(\Gamma)\right]$ is the recombination of $2 L A(M)$ and $E_{2 \mathrm{~g}}^{1}(\Gamma)$ modes, or the mode without multi-Lorentzian fitting. The peak intensity of Rec.[2LA(M), $\left.E_{2 \mathrm{~g}}^{1}(\Gamma)\right], 2 L A(M), E_{2 \mathrm{~g}}^{1}(\Gamma)$, and $A_{1 \mathrm{~g}}(\Gamma)$ as a function of temperature for $1 \mathrm{~L}, \mathrm{FL}$, and bulk $\mathrm{WS}_{2}$ films can be referred to Fig. 5. With the temperature decreasing,
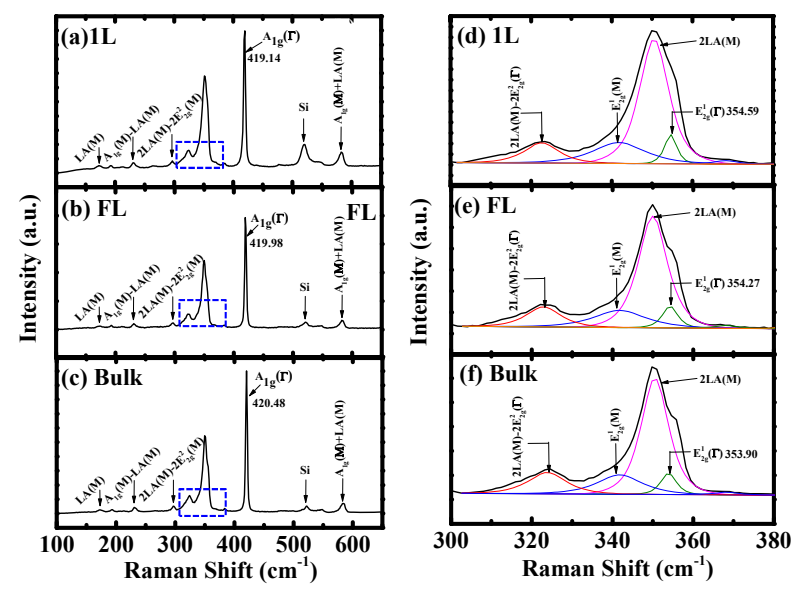

Fig. 3 Raman spectra at $300 \mathrm{~K}$ of (a) $1 \mathrm{~L}$, (b) FL, and (c) bulk $\mathrm{WS}_{2}$ film under a $514 \mathrm{~nm}$ excitation laser. Multi-Lorentzian fitting of $2 L A(M)-$ $2 E_{2 \mathrm{~g}}^{2}(\Gamma), E_{2 \mathrm{~g}}^{1}(M), 2 L A(M)$, and $E_{2 \mathrm{~g}}^{1}(\Gamma)$ modes for (d) $1 \mathrm{~L}$, (e) FL, and (f) bulk WS film, respectively. 


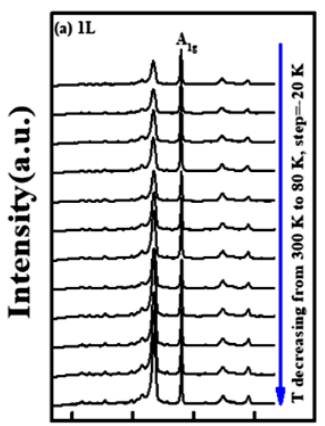

150300450600 Raman shift $\left(\mathrm{cm}^{-1}\right)$

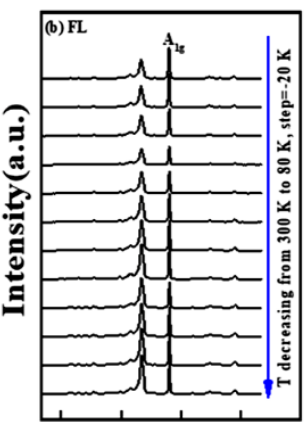

150300450600 Raman shift $\left(\mathrm{cm}^{-1}\right)$

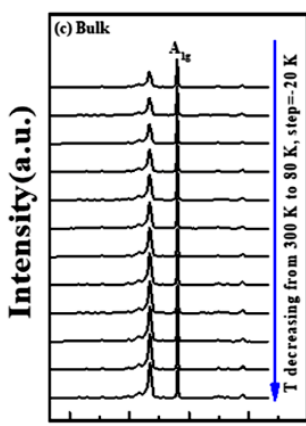

150300450600 Raman shift $\left(\mathrm{cm}^{-1}\right)$

Fig. 4 Temperature-dependent Raman measurements of (a) 1L, (b) FL, and (c) bulk WS films at 80-300 K under a $514 \mathrm{~nm}$ excitation laser.
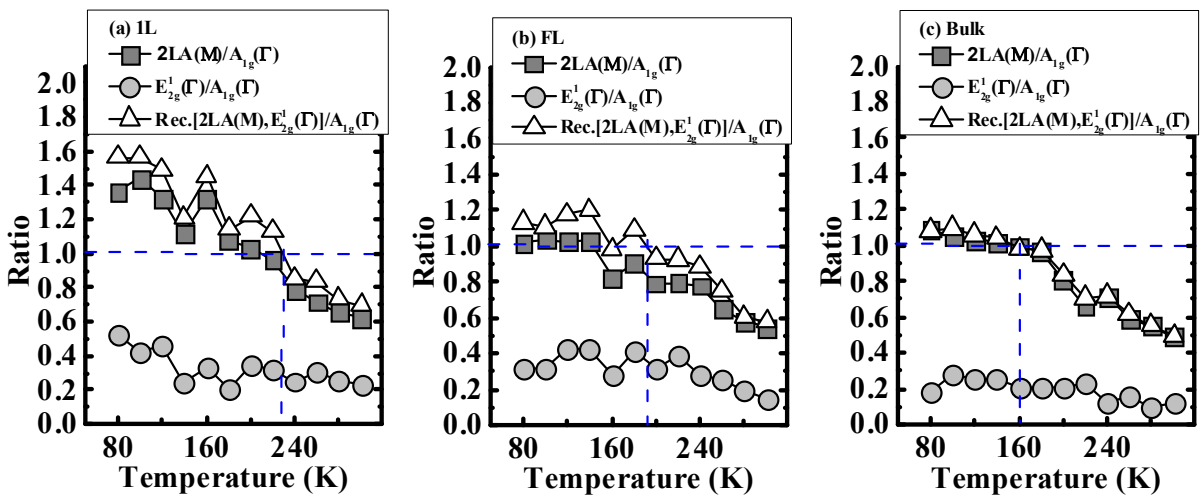

Fig. $52 L A(M) / A_{1 \mathrm{~g}}(\Gamma), E_{2 \mathrm{~g}}^{1}(\Gamma) / A_{1 \mathrm{~g}}(\Gamma)$, and Rec. $\left[2 L A(M), E_{2 \mathrm{~g}}^{1}(\Gamma)\right] / A_{1 \mathrm{~g}}(\Gamma)$ peak intensity ratios as a function of temperature for (a) $1 \mathrm{~L}$,

(b) FL, and (c) bulk WS $\mathrm{W}_{2}$ films.

It is noted that the Rec.[2LA(M), $\left.E_{2 \mathrm{~g}}^{1}(\Gamma)\right] / A_{\mathrm{lg}}(\Gamma)$ ratio is creased to more than 1 at 230,190 , and $160 \mathrm{~K}$, respectively, for $1 \mathrm{~L}$, FL, and bulk WS films

the Raman intensities of Rec. [2LA(M), $\left.E_{2 \mathrm{~g}}^{1}(\Gamma)\right], 2 L A(M), E_{2 \mathrm{~g}}^{1}(\Gamma)$, and $A_{\lg }(\Gamma)$ are increasing at different rates for $1 \mathrm{~L}, \mathrm{FL}$, and bulk $\mathrm{WS}_{2}$ films. As shown in Fig. 5, it is noted that the Rec. [2LA(M), $\left.E_{2 \mathrm{~g}}^{1}(\Gamma)\right] / A_{1 \mathrm{~g}}(\Gamma)$ intensity ratio is creased to more than 1 at 230 , 190 , and $160 \mathrm{~K}$, respectively, for $1 \mathrm{~L}, \mathrm{FL}$, and bulk $\mathrm{WS}_{2}$ films. The $A_{1 \mathrm{~g}}(\Gamma)$ vibration mode, related to the out-of-plane vibration of sulfur atoms, is dominated when the temperature is above the "cross-over" point or intensity ratio more than 1; Rec.[2LA(M), $\left.E_{2 \mathrm{~g}}^{1}(\Gamma)\right]$ mode, related to film disorder and in-plane vibration of tungsten and sulfur atoms, is dominated when the temperature is below "cross-over" point or intensity ratio less than 1 . The "cross-over" phenomenon is mainly caused by the fast increasing intensity of $2 L A(M)$ mode as the temperature decreasing. Based on the "cross-over" temperature, it may be possible to determine the layer number of $\mathrm{WS}_{2}$ films, since it shows layer-dependent behavior, although more detailed work is needed.

When the temperature decreasing from 300 to $80 \mathrm{~K}$, all the Raman modes of $2 L A(M), E_{2 \mathrm{~g}}^{1}(\Gamma), A_{1 \mathrm{~g}}(\Gamma)$, and $A_{1 \mathrm{~g}}(M)+L A(M)$ for $1 \mathrm{~L}, \mathrm{FL}$, and bulk $\mathrm{WS}_{2}$ films change linearly as a function of temperature, shown in Fig. 6a, b, c, and d. It is well-known that Raman spectroscopy is a photon-phonon process which is dominant over thermal expansion, as well as the phonon process on the Raman mode linearly shifts with change in temperature. A few data point dispersion for the Raman peak position can be expected and is well-understood due to the slight variation in the laser spot on the sample, or the local Raman stage vibration, or low excitation power on the sample followed by the extra attenuation from the cold-hot cell window during the measurement. The observed data of peak position obtained from Lorentzian fitting for $2 L A(M), E_{2 \mathrm{~g}}^{1}(\Gamma), A_{1 \mathrm{~g}}(\Gamma)$, and $A_{1 \mathrm{~g}}(M)+$ $L A(M)$ modes versus temperature were fitted using the Grüneisen model: $\omega(T)=\omega_{0}+X T$, where $\omega_{0}$ is the Raman mode peak position at zero Kelvin temperature, and $X$ is the first-order temperature coefficient of the same mode. The slope of fitted lines gives the first-order temperature coefficient of the specific Raman mode, and shown as an inset in Fig. 6. $X$ values of $2 L A(M), E_{2 \mathrm{~g}}^{1}(I)$, and $A_{1 \mathrm{~g}}(\Gamma)$ modes for the $1 \mathrm{~L} \mathrm{WS}_{2}$ are larger than those of FL and bulk $\mathrm{WS}_{2}$, shown in Fig. 6a, b, and c. However, $X\left(\sim-0.010 \mathrm{~cm}^{-1} \cdot \mathrm{K}^{-1}\right)$ of $A_{1 \mathrm{~g}}(M)+L A(M)$ mode is almost identical for $1 \mathrm{~L}, \mathrm{FL}$, and bulk $\mathrm{WS}_{2}$. Table 1 summarizes the extracted first-order temperature coefficient of $L A(M), 2 L A(M)$ $-2 E_{2 \mathrm{~g}}^{2}(I), E_{2 \mathrm{~g}}^{1}(M), 2 L A(M), E_{2 \mathrm{~g}}^{1}(I), A_{1 \mathrm{~g}}(\Gamma)$, and $A_{1 \mathrm{~g}}(M)+L A(M)$, for $1 \mathrm{~L}, \mathrm{FL}$, and bulk $\mathrm{WS}_{2}$. The $X$ values for the $2 L A(M), A_{\mathrm{gg}}(\Gamma)$, and $A_{1 \mathrm{~g}}(M)+L A(M)$ modes of $1 \mathrm{~L} \mathrm{WS}_{2}$ in this work were observed to be close or nearly same as the reported one by Thripuranthaka et al. ${ }^{34}$. The $X$ variation of $E_{2 \mathrm{~g}}^{1}(\Gamma)$ between this work and Ref. ${ }^{34}$ could be due to the error caused by multiLorentzian fitting. Also, the reported $X$ for $E_{2 \mathrm{~g}}^{1}(\Gamma)$ and $A_{1 \mathrm{~g}}(\Gamma)$ modes of $1 \mathrm{~L} \mathrm{WS} 2$ grown by CVD method is -0.0125 and 

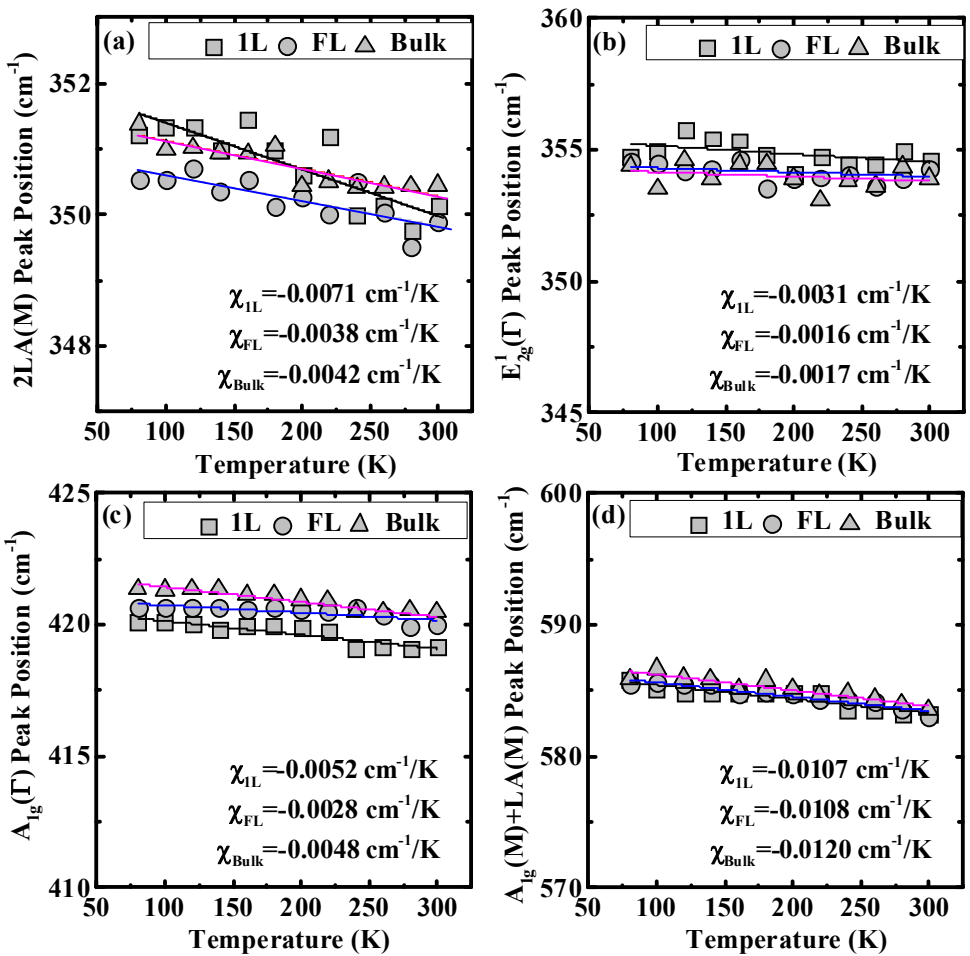

Fig. 6 Effect of temperature variation on the Raman modes of (a) $2 L A(M)$, (b) $E_{2 \mathrm{~g}}^{1}(\Gamma)$, (c) $A_{1 \mathrm{~g}}(\Gamma)$, and (d) $A_{1 \mathrm{~g}}(M)+L A(M)$ for 1L, FL, and bulk WS $\mathrm{W}_{2}$ films.

Table 1 Extracted temperature coefficient $X$ for $1 \mathrm{~L}, \mathrm{FL}$, and bulk $\mathrm{WS}_{2}$ films.

\begin{tabular}{|c|c|c|c|c|c|}
\hline $1 \mathrm{~L} \mathrm{WS}_{2}$ & $X /\left(\mathrm{cm}^{-1} \cdot \mathrm{K}^{-1}\right)$ & $\mathrm{FL} \mathrm{WS}_{2}$ & $X /\left(\mathrm{cm}^{-1} \cdot \mathrm{K}^{-1}\right)$ & Bulk WS 2 & $X /\left(\mathrm{cm}^{-1} \cdot \mathrm{K}^{-1}\right)$ \\
\hline $\mathrm{LA}(\mathrm{M})$ & -0.0090 & LA(M) & -0.0025 & $\mathrm{LA}(\mathrm{M})$ & -0.0041 \\
\hline $2 L A(M)-2 E_{2 \mathrm{~g}}^{2}(\Gamma)$ & -0.0039 & $2 L A(M)-2 E_{2 \mathrm{~g}}^{2}(\Gamma)$ & -0.0001 & $2 L A(M)-2 E_{2 \mathrm{~g}}^{2}(\Gamma)$ & -0.0001 \\
\hline$E_{2 \mathrm{~g}}^{1}(M)$ & -0.0047 & $E_{2 \mathrm{~g}}^{1}(M)$ & -0.0010 & $E_{2 \mathrm{~g}}^{1}(M)$ & -0.0008 \\
\hline $2 L A(M)$ & -0.0071 & $2 L A(M)$ & -0.0038 & $2 L A(M)$ & -0.0042 \\
\hline$E_{2 \mathrm{~g}}^{1}(\Gamma)$ & -0.0031 & $E_{2 \mathrm{~g}}^{1}(\Gamma)$ & -0.0016 & $E_{2 \mathrm{~g}}^{1}(\Gamma)$ & -0.0017 \\
\hline$A_{\lg }(\Gamma)$ & -0.0052 & $A_{\lg (\Gamma)}$ & -0.0028 & $A_{1 \mathrm{~g}}(\Gamma)$ & -0.0048 \\
\hline$A_{\lg }(M)+L A(M)$ & -0.0107 & $A \lg (M)+L A(M)$ & -0.0108 & $A \lg (M)+L A(M)$ & -0.0120 \\
\hline
\end{tabular}

$-0.0149 \mathrm{~cm}^{-1} \cdot \mathrm{K}^{-1}$, respectively, which is larger or one order magnitude higher than the ones reported in this work and Ref. ${ }^{34}$. In addition, the reported $X$ for and $E_{2 \mathrm{~g}}^{1}$ and $A_{1 \mathrm{~g}}$ modes of $1 \mathrm{~L} \mathrm{MoS}_{2}$ by mechanical exfoliation method, is $\sim-0.017$ and $\sim-0.013$ $\mathrm{cm}^{-1} \cdot \mathrm{K}^{-1}$, respectively, which is larger or one order magnitude higher than the ones reported in this work and Ref. ${ }^{39-41}$. This indicates that the thermal stability of $\mathrm{WS}_{2}$ may be better than that of $\mathrm{MoS}_{2}$, based on the first-order temperature coefficient of the Raman modes. As compared to $X\left(\sim-0.0162 \mathrm{~cm}^{-1} \cdot \mathrm{K}^{-1}\right)$ of $G$ peak for $1 \mathrm{~L}$ graphene by mechanical exfoliation, $X$ of $1 \mathrm{~L} \mathrm{WS}_{2}$ in this work is also about one order magnitude lower. With the combination of lower in-plan electronic mass and higher thermal stability (or lower temperature coefficient) ${ }^{42}, \mathrm{WS}_{2}$ could serve as a better candidate for Si CMOS channel material beyond sub$22 \mathrm{~nm}$, as compared to other TMDs. By now, temperaturedependent Raman studies have not been carried out for FL and bulk WS $\mathrm{W}_{2}$ films by mechanical exfoliation in the literature. The presence of substrate $300 \mathrm{~nm} \mathrm{SiO} / / \mathrm{Si}$ in this work may not affect the final results of temperature coefficient a lot. The effect of substrate on temperature coefficient of $\mathrm{WS}_{2}$ grown by CVD has been investigated by Peimyoo et al. ${ }^{39}$, and only gives about $6 \%$ variation. It is interesting to note that we did not observe the dependence of FWHM on the temperature in the examined temperature range in the $1 \mathrm{~L}, \mathrm{FL}$, and bulk $\mathrm{WS}_{2}$ samples. This is in contrast with the $A_{1 \mathrm{~g}}$ FWHM temperature dependent for $\mathrm{MoS}_{2}$. Further, the variation in the Raman peak position as a function of temperature for the $1 \mathrm{~L}, \mathrm{FL}$, and bulk $\mathrm{WS}_{2}$ samples is due to the temperature contribution that consequences from anharmonicity and contribution from the thermal expansion or volume contribution.

\section{Conclusions}

We have systematically investigated the thickness- and temperature-dependent Raman studies of the phonon vibration mode for mono-layer (1L), few-layer (FL), and bulk $\mathrm{WS}_{2}$ films prepared by mechanical exfoliation. With the film thickness increasing to bulk, $A_{1 \mathrm{~g}}(\Gamma)$ and $E_{2 \mathrm{~g}}^{1}(\Gamma)$ modes show blue-shift of $1.34 \mathrm{~cm}^{-1}$ and red-shift of $0.69 \mathrm{~cm}^{-1}$, respectively, with respect 
to $1 \mathrm{~L} \mathrm{WS}_{2}$. With temperature decreasing, all the Raman peak positions shift to a higher energy. The "cross-over" temperature, when the dominant Raman vibration modes swaps between $E_{2 \mathrm{~g}}^{1}(\Gamma)$ and $A_{1 \mathrm{~g}}(\Gamma)$, was identified to be 230,190 , and $160 \mathrm{~K}$, respectively, for $1 \mathrm{~L}, \mathrm{FL}$, and bulk $\mathrm{WS}_{2}$ films. As compared to $\mathrm{MoS}_{2}, \mathrm{WS}_{2}$ shows much smaller frequency change (64.55-66.58 $\mathrm{cm}^{-1}$ ) between $E_{2 \mathrm{~g}}^{1}(\Gamma)$ and $A_{1 \mathrm{~g}}(\Gamma)$ as the film thickness varying, and one magnitude lower temperature coefficient of Raman peak position or better thermal stability. Through this systematic study, the results shown here provide a physical guidance for WS2-based device engineering.

\section{References}

(1) Ramakrishna Matte, H. S. S.; Gomathi, A.; Manna, A. K.; Late, D. J.; Datta, R.; Pati, S. K.; Rao, C. N. R. Angew. Chem. Int. Edit. 2010, 49 (24), 4059. doi: 10.1002/anie.201000009

(2) Wang, Q. H.; Kalantar-Zadeh, K.; Kis, A.; Coleman, J. N.; Strano, M. S. Nat. Nanotech. 2012, 7, 699. doi: 10.1038/nnano.2012.193

(3) Novoselov, K. S.; Jiang, D.; Schedin, F.; Booth, T. J.; Khotkevich, V. V.; Morozov, S. V.; Geim, A. K. Proc. Natl. Acad. Sci. U.S.A. 2005, 102 (30), 10451. doi: 10.1073/pnas.0502848102

(4) Chhowalla, M.; Shin, H. S.; Eda, G.; Li, L. J.; Loh, K. P.; Zhang, H. Nat. Chem. 2013, 5, 263. doi: 10.1038/nchem.1589

(5) Perea-López, N.; Elías, A. L.; Berkdemir, A.; Castro-Beltran, A.; Gutiérrez, H. R.; Feng, S.; Lv, R.; Hayashi, T.; López-Urías, F.; Ghosh, S.; et al. Adv. Funct. Mater. 2013, 23 (44), 5511. doi: 10.1002/adfm.201300760

(6) Mak K F, He K, Shan J,Heinz T F. Nat. Nanotech. 2012, 7, 494. doi: 10.1038/nnano.2012.96

(7) Zeng, H.; Dai, J.; Yao, W.; Xiao, D.; Cui, X. Nat. Nanotech. 2012, 7, 490. doi: $10.1038 /$ nnano.2012.95

(8) Wu, S.; Ross, J. S.; Liu, G. B.; Aivazian, G.; Jones, A.; Fei, Z.; Zhu, W.; Xiao, D.; Yao, W.; Cobden, D.; et al. Nat. Phys. 2013, 9, 149. doi: $10.1038 /$ nphys 2524

(9) Novoselov, K. S.; Geim, A. K.; Morozov, S. V.; Jiang, D.; Zhang, Y.; Dubonos, S. V.; Grigorieva, I. V.; Firsov, A. A. Science 2004, 306 (5696), 666. doi: 10.1126/science.1102896

(10) Bolotin, K. I.; Sikes, K. J.; Jiang, Z.; Klima, M.; Fudenberg, G.; Hone, J.; Kim, P.; Stormer, H. L. Solid State Commun. 2008, 146 (9), 351. doi: 10.1016/j.ssc.2008.02.024

(11) Han, M. Y.; Özyilmaz, B.; Zhang, Y.; Kim, P. Phys. Rev. Lett. 2007, 98 (20), 206805. doi: 10.1103/PhysRevLett.98.206805

(12) Li, X.; Wang, X.; Zhang, L.; Lee, S.; Dai, H. Science 2008, 319 (5867), 1229. doi: 10.1126/science. 1150878

(13) Zhang, Y.; Tang, T. T.; Girit, C.; Hao, Z.; Martin, M. C.; Zettl, A.; Crommie, M. F.; Shen, Y. R.;Wang, F. Nature 2009, 459, 820. doi: $10.1038 /$ nature 08105
(14) Jiao, L.; Zhang, L.; Wang, X.; Diankov, G.; Dai, H. Nature 2009, 458, 877. doi: 10.1038/nature07919

(15) Sols, F.; Guinea, F. Neto, A. H. C. Phys. Rev. Lett. 2007, 99 (16), 166803. doi: 10.1103/PhysRevLett.99.166803

(16) Yoon, Y.; Guo, J. Appl. Phys. Lett. 2007, 91 (7), 073103. doi: $10.1063 / 1.2769764$

(17) Cheng, R.; Jiang, S.; Chen, Y.; Liu, Y.; Weiss, N.; Cheng, H. C.; Wu, H.; Huang, Y.; Duan, X. Nat. Commun. 2014, 5, 5143. doi: $10.1038 /$ ncomms6143

(18) Yoon, Y.; Ganapathi, K.; Salahuddin, S. Nano Lett. 2011, 11 (9), 3768. doi: $10.1021 / \mathrm{nl} 2018178$

(19) Radisavljevic, B.; Radenovic, A.; Brivio, J.; Giacometti, V.; Kis, A. Nat. Nanotech. 2011, 6, 147. doi: 10.1038/nnano.2010.279

(20) Radisavljevic, B.; Kis, A. Nat. Mater. 2013, 12, 815. doi: $10.1038 /$ nmat 3687

(21) Schmidt, H.; Wang, S.; Chu, L.; Toh, M.; Kumar, R.; Zhao, W.; Castro Neto, A. H.; Martin, J.; Adam, S.; Özyilmaz, B. Eda G. Nano Lett. 2014, 14 (4), 1909. doi: 10.1021/n14046922

(22) Ghatak, S.; Pal, A. N.; Ghosh, A. ACS Nano 2011, 5 (10), 7707. doi: $10.1021 / \mathrm{nn} 202852 \mathrm{j}$

(23) Gong, Y.; Lin, J.; Wang, X.; Shi, G.; Lei, S.; Lin, Z.; Zou, X.; Ye, G.; Vajtai, R.; Yakobson, B. I.; et al. Nat. Mater. 2014, 13, 1135. doi: $10.1038 /$ nmat4091

(24) Das, S.; Chen, H. Y.; Penumatcha, A. V.; Appenzeller. J. Nano Lett. 2013, 13 (1), 100. doi:10.1021/n1303583v

(25) Bikorimana, S.; Lama, P.; Walser, A.; Dorsinville, R.; Anghel, S.; Mitioglu, A.; Micu, A.; Kulyuk, L. Opt. Express. 2016, 24 (18), 20685. doi: 10.1364/OE.24.020685

(26) Gu, H.; Chen, L.; Lu, Y.,Tian, F. ; Zhang, Z., Xu, K.; Wu, J.; Divakar,V.B.; Li,K., Liu, L. Jpn. J. Appl. Phys. 2018, 57 (6), 060309. doi: 10.7567/JJAP.57.060309

(27) Liu, L.; Kumar, S. B.; Ouyang, Y.; Guo, J. IEEE T. Electron Dev. 2011, 58 (9), 3042. doi: 10.1109/TED.2011.2159221

(28) Ovchinnikov, D.; Allain, A.; Huang, Y. S.; Dumcenco, D.; Kis, A. ACS Nano 2014, 8 (8), 8174. doi: 10.1021/nn502362b

(29) Liu, X.; Hu, J.; Yue, C.; Della Fera, N.; Ling, Y.; Mao, Z.; Wei, J. ACS Nano 2014, 8 (10), 10396. doi: 10.1021/nn505253p

(30) Kim, Y. J.; Park, W.; Yang, J. H.; Kim, Y.; Lee, B. H. IEEE J. Electron Devi. 2018, 6, 164. doi: 10.1109/JEDS.2017.2781250

(31) Calizo, I.; Balandin, A. A.; Bao, W.; Miao, F.; Lau, C. N. Nano Lett. 2007, 7 (9), 2645. doi: 10.1021/n1071033g

(32) Kaasbjerg, K.; Thygesen, K. S.; Jacobsen, K. W. Phys. Rev. B 2012, 85 (11), 115317. doi: 10.1103/PhysRevB.85.115317

(33) Lee, C.; Yan, H.; Brus, L. E.; Heinz, T. F.; Hone, J.; Ryu, S. ACS Nano 2010, 4 (5), 2695. doi: 10.1021/nn1003937

(34) Thripuranthaka,M.; Late, D. J. ACS Appl. Mater. Inter. 2014, 6 (2), 1158. doi: $10.1021 / \mathrm{am} 404847 \mathrm{~d}$ 
(35) Thripuranthaka, M.; Kashid, R. V.; Rout, C. S.; Late, D. J. Appl. Phys. Lett. 2014, 104 (8), 081911. doi: 10.1063/1.4866782

(36) Gutiérrez, H. R.; Perea-López, N.; Elías, A. L.; Berkdemir, A.; Wang, B.; Lv, R.; López-Urías, F.; Crespi, V. H.; Terrones, H.; Terrones, M. Nano Lett. 2013, 13 (8), 3447. doi: 10.1021/n13026357

(37) Berkdemir, A.; Gutiérrez, H. R.; Botello-Méndez, A. R.; PereaLópez, N.; Elías, A. L.; Chia, C. I.; Wang, B.; Crespi, V. H.; LópezUrías, F.; Charlier, J. C.; et al. Sci. Rep. 2013, 3, 1755. doi: $10.1038 /$ srep01755

(38) Peimyoo, N.; Shang, J.; Yang, W.; Wang, Y.; Cong, C.; Yu, T. Nano
Res. 2015, 8 (4), 1210. doi: 10.1007/s12274-014-0602-0

(39) Lanzillo, N. A.; Birdwell, A. G.; Amani, M.; Crowne, F. J.; Shah, P. B.; Najmaei, S.; Liu, Z.; Ajayan, P. M.; Lou, J.; Dubey, M.; et al. Appl. Phys. Lett. 2013, 103 (9), 093102. doi: 10.1063/1.4819337

(40) Sahoo, S.; Gaur, A. P. S.; Ahmadi, M.; Guinel, M. J. F.; Katiyar, R. S. J. Phys. Chem. C 2013, 117 (17), 9042. doi: 10.1021/jp402509w

(41) Najmaei, S.; Ajayan, P. M.; Lou, J. Nanoscale 2013, 5 (20), 9758. doi: $10.1039 / \mathrm{C} 3 \mathrm{NR} 02567 \mathrm{E}$

(42) Feng, X.; Kulish, V. V.; Wu, P.; Liu, X.; Ang, K. W. Nano Res. 2016, 9 (9), 2687. doi: 10.1007/s12274-016-1156-0 